Научная статья

УДк 159.913

DOI https://doi.org/10.24866/VVSU/2073-3984/2021-3/197-206

И.И. Черемискина

Владивостокский государственный университет экономики и сервиса

Владивосток. Россия

\title{
Оптимизм и активность как ресурсы нормализации психического состояния у молодых людей в период пандемии и самоизоляции
}

\begin{abstract}
Каждый из нас ежедневно испытывает определенную стрессовую нагрузку, так называемый повседневный стресс, с которым мы привыкли справляться, однако пандемия COVID-19 и связанные с ней ограничения значительно изменили привычный уклад жизни многих из нас, и, как отмечают ученые-психологи, стрессовая нагрузка на население всего мира была многократно превышена. Доминирующими состояниями у многих людей стали страх, тревога, чувство неопределенности будущего. Такая ситуация обусловлена как объективными факторами: информационным давлением, депривацией, социально-экономической нестабильностью, так и личностными особенностями, то есть субъективными факторами. Поиск ресурсов нормализации психического состояния людей во время пандемии и самоизоляции стал одной из актуальных задач практических психологов. В данной статье представлены результаты исследования доминирующего психического состояния молодых людей в период пандемии и самоизоляции и связи его параметров с такими личностными чертами, как оптимизм и активность. В психологии имеются научные данные о том, что эти качества в целом способствуют высокому психологическому благополучию людей. Исследование проводилось дистанционно с помощью тест-опросников. В результате было выявлено, что большинство молодых людей, принявших участие в исследовании, относятся к типу личности «пассивные пессимисты», у них зафиксированы низкие показатели оптимизма и активности, что связано с их негативным психическим состоянием во время пандемии и самоизоляции. Показано, что высокая личностная активность способствует выбору оптимальных стратегий преодоления и нормализации психического состояния. Сбалансированный оптимизм позволил молодым людям сохранять спокойствие в указанный период. Высокие показатели оптимизма, наоборот, способствовали росту тревоги и беспокойства. Полученные данные позволили расширить теоретические представления об оптимизме и активности личности как ресурсах преодоления стресса, а также
\end{abstract}

Черемискина Ирина Игоревна - канд. психол. наук, доцент кафедры философии и юридической психологии; e-mail: irina-cheremiski@mail.ru 
могут быть использованы при создании программ профилактики неоптимальных состояний у молодых людей в периоды повышенных стрессовых нагрузок.

Ключевые слова и словосочетания: пандемия и самоизоляция, негативное психическое состояние, ресурсы преодоления негативных состояний, черты личности, оптимизм и активность, молодые люди.

\title{
I. I. Cheremiskina
}

Vladivostok State University of Economics and Service

Vladivostok. Russia

\section{Optimism and activism as resources for normalizing mental health in young people during pandemic and self-isolation}

\begin{abstract}
Each of us faces a certain amount of daily stress, so-called daily stress, that we are accustomed to dealing with, but the COVID-19 pandemic and its associated limitations have significantly changed the way of life of many of us and, as the psychologists have noted, The stress on the world's population has been multiplied. Fear, anxiety, a sense of uncertainty about the future have become dominant in many people. This situation is due both to objective factors: information pressure, deprivation, social and economic instability, and to personal characteristics, that is, subjective factors. The search for resources to normalize the mental state of people during a pandemic and self-isolation has become one of the urgent tasks of practical psychologists. This article presents the results of a study of the dominant mental condition of young people during a pandemic and selfisolation, and how its parameters relate to personality traits such as optimism and activity. There is scientific evidence in psychology that these qualities generally contribute to the high psychological well-being of people. The study was conducted remotely by means of a test questionnaire. As a result, it was found that most of the young people who took part in the study belong to the personality type "passive pessimists", they have low levels of optimism and activity, It's related to their negative mental state during the pandemic and self-isolation. It is also shown that high personal activity contributes to the choice of optimal strategies for overcoming and normalizing mental state. A balanced optimism allowed young people to remain calm during this period.On the contrary, high levels of optimism have contributed to growing anxiety and anxiety. The findings have broadened the theoretical understanding of individual optimism and activity as a stress-management resource and can be used to create programmes to prevent suboptimal states in young people during periods of increased stress.
\end{abstract}

Keywords: pandemic and self-isolation, negative mental state, resources to overcome negative state, personality traits, optimism and activity, young people.

\section{Введение}

Пандемия COVID-19 стала серьезным испытанием для всего мирового сообщества. Практика показала, что, несмотря на высокий уровень технического и медицинского развития многих стран, справиться с опасностью вирусного заражения в короткие сроки не представилось возможным. Помимо физического 
воздействия на заболевших и последствий для здоровья перенесших заболевание, COVID-19 оказывает серьезное влияние на психическое состояние всех людей. Именно поэтому психологи оперативно отреагировали на сложившуюся ситуацию и провели исследования, результаты которых легли в основу разработки программ психологической помощи населению в сложившихся условиях пандемии, прежде всего самоизоляции.

Как оказалось, в психологической науке уже имеются данные о психическом состоянии людей во время активного воздействия вирусов. Например, во время вспышки Эболы в 2008 году наблюдался широкий спектр психологических последствий на индивидуальном, общественном, национальном и международном уровнях. На индивидуальном уровне люди испытывали страх заболеть или умереть, чувство беспомощности и недоверия со стороны других людей [8]. Пандемия COVID-19 оказала пагубное воздействие на психическое здоровье населения, что впоследствии может привести к психосоциальным кризисам [9]. Такие кризисы здоровья, как пандемия COVID-19, приводят к психологическим изменениям не только у медицинских работников в связи с высокой нагрузкой и опасностью заражения, но и у обычных граждан, эти психологические изменения провоцируются страхом, тревогой, депрессией или неуверенностью в себе [10]. Распознавание неоптимальных состояний у населения дает возможность создавать и применять профилактические мероприятия, что и обусловливает актуальность данного исследования.

Поиск ресурсов преодоления неоптимальных психических состояний и их эффективное использование представляют для психологов приоритетную задачу, особенно в ситуациях высокой стрессовой нагрузки на население. Результаты данного исследования позволяют понять, насколько оптимизм и активность личности являются личностными ресурсами нормализации психического состояния в период пандемии и самоизоляции, и в дальнейшем разработать эффективные профилактические, просветительские и развивающие психологические мероприятия, которые могут быть реализованы в любое время не только для помощи населению в преодолении возникающих неоптимальных состояний, но и развития личностных ресурсов, обусловливающих устойчивость к подобного рода событиям. Данный факт обеспечивает практическую значимость работы.

Предметом исследования стало психическое состояние у молодых людей с разным уровнем оптимизма и активности в период пандемии и самоизоляции. Изучение психических состояний в психологии имеет давнюю историю. Н.Д. Левитов определяет психическое состояние как целостную характеристику психической деятельности человека за определенный промежуток времени, которая отражает своеобразие протекания психических процессов в зависимости от окружающей ситуации, предшествующего состояния и свойств личности. Он указывает на то, что учет особенностей протекания психических состояний в зависимости от действующих на человека явлений имеет высокую ценность для понимания психической жизни человека в целом [5]. Важными особенностями в понимании психического состояния, по Н. Д. Левитову, являются его объективная обусловленность, а также обусловленность устойчивыми характеристиками 
личности самого человека. Е. Ю. Сосновикова также отмечает, что психические состояния являются реакциями человека на изменение среды, в которой он функционирует в определенный период времени. По её мнению, психические состояния можно рассматривать как отдельные психологические феномены, наделенные определенного рода качествами, особенностями и характеристиками как таковыми [8]. А.О. Прохоров считает, что психическое состояние является синдромом (комплексом симптомов) в определенный временной период, в таком аспекте психические состояния проявляются в единстве поведения и переживания человека [7]. Е. П. Ильин описывает три уровня проявлений психических состояний человека: поведенческий, психологический и физиологический. Физиологический уровень психического состояния выражается в наличии у человека определенного рода проявлений вегетативного или соматического характера. Психологический уровень психических состояний выражается в переживаниях и особенностях протекания психических процессов. Поведенческий уровень психических состояний выражается в особенностях общения, осуществления деятельности, поведения в целом [4].

По модальности влияния на человека Н. Д. Левитов делит состояния на положительные и отрицательные. Положительные психические состояния благоприятным образом сказываются на жизнедеятельности человека, на осуществляемой им деятельности и повышают общую благоприятность состояния человека. Негативные состояния, напротив, отрицательным образом сказываются на деятельности человека, ухудшая ее [5].

Можно сказать, что пандемия COVID-19 стала тем объективным событием, которое вызвало многообразие отрицательных состояний у всей мировой общественности и, в частности, у жителей России. Подобная ситуация обусловлена обстоятельствами во многом уникальными, принципиально новыми, создающими многомерность психосоциальных стрессовых воздействий вокруг центрального стрессогенного фактора угрозы для жизни.

Современные исследователи выявили и описали следующие:

1. Виртуальная угроза и информачионный стресс. Информационное давление, оказываемое во всем мире в связи с пандемией, чрезвычайно сильно, а психотравмирующий характер содержания информационных сообщений заслуживает самостоятельного изучения. Люди столкнулись с переполненным противоречивыми сведениями информационным пространством, что, безусловно, травматично для психики человека. Строгие карантинные меры, введенные в большинстве стран в связи с пандемией коронавируса, являются беспрецедентными. Требование самоизоляции и иные ограничения, призванные предотвратить распространение инфекции, серьезно деформировали привычный жизненный уклад большинства граждан, затронув потребности разных уровней: от витальных до высших, что явно привело к депривационному стрессу. Пандемия нанесла мощный удар по мировой экономике, затронув практически все ее отрасли. Социально-экономический стресс, переживаемый большинством граждан во время самоизоляции и по сей день, обусловлен, с одной стороны, общей озабоченностью экономическими последствиями пандемии и ожиданием экономического 
коллапса, а с другой - реальными финансовыми трудностями и потерей финансовой, профессиональной стабильности значительной долей трудоспособного населения $[1 ; 6]$. Таким образом, поиск и развитие ресурсов, способствующих нормализации психического состояния во время пандемии и самоизоляции, являются значимой практической задачей для психологов.

В общем понимании личностные ресурсы преодоления негативных психических состояний представляют собой стабильные личностные характеристики, способствующие этому преодолению. Многие исследователи к важным личностным ресурсам относят способы совладания со стрессом, самооценку и самоэффективность, чувство согласованности, уровень оптимизма, способность действовать и локус контроля. Н. Е. Водопьянова описывает ресурсы преодоления стрессовых событий как внутренние и внешние переменные, способствующие психологической устойчивости в стрессогенных ситуациях. Под этими переменными понимаются эмоциональные, мотивационно-волевые, когнитивные и поведенческие конструкты, которые человек актуализирует для адаптации к стрессогенным/стрессовым трудовым и жизненным ситуациям, средства (инструменты), используемые им для трансформации взаимодействия со стрессогенной ситуацией. В выполненном Н.Е. Водопьяновой и её коллегами исследовании было установлено, что существуют взаимосвязи между психологическим благополучием личности и показателями субъективной жизненной позиции, в частности, активностью и оптимизмом. Было установлено, что уровень психологического благополучия личности достоверно выше у тех лиц, которые характеризуются высоким уровнем оптимизма и активности [3].

Ж. А. Барсукова рассматривала оптимизм и диспозиционную надежду как ресурсы преодоления стрессовых ситуаций студентов. В ходе проведенного исследования было определено, что большинство студентов-первокурсников могут быть отнесены к категории «пассивных пессимистов», то есть они избегают активного изменения ситуации, которая характеризуется напряженностью, однако в процессе обучения в вузе ситуация немного меняется, увеличивается число активных пессимистов, что проявляется в ориентации на удачу и везение, а не на конструктивное решение проблем [2]. Таким образом, можно предположить, что в связи с личностными особенностями молодых людей они в ситуации стресса (пандемии и самоизоляции) будут испытывать преимущественно негативные психические состояния.

Методы исследования. Выборка проведенного эмпирического исследования составила 39 молодых людей в возрасте от 18 до 29 лет (26 женщин и 13 мужчин), обучающихся в вузах на разных направлениях подготовки, работающих по разным специальностям. Исследование было проведено с 02.04.2020 по 30.05.2020 года. Ввиду неблагоприятной эпидемиологической обстановки в Приморском крае исследование проводилось в онлайн-формате: все необходимые для проведения исследования методики были преобразованы для использования и проведения в электронном формате. Респондентам, согласившимся принять участие в исследовании, были высланы электронные бланки следующих методик: «Тест-опросник актуального состояния» Л. В. Куликова, «Рельеф пси- 
хического состояния» А. О. Прохорова, «Опросник оптимизма и активности» Н. Е. Водопьянова, М. В. Штейн. Все используемые в исследовании методики являются опросниками. Главное их достоинство - простота в применении и обработке, что значительно облегчило их перевод в Google форму. Для статистической обработки полученных данных использовались непараметрический критерий оценки значимости различий между имеющимися параметрами, полученными на трех и более независимых выборках Крускалла-Уоллиса, и коэффициент ранговой корреляции Ч. Спирмена, расчеты проводились в статистическом пакете прикладных программ SPSS20.0.

Основная часть. Опросник оптимизма и активности Н. Е. Водопьяновой и М. В. Штейн содержит две шкалы: «оптимизм-пессимизм», «активностьпассивность». Полученные по этим шкалам данные позволяют отнести отдельного респондента к одному из 5 типов личности: «активные оптимисты», «пассивные пессимисты», «активные пессимисты», или «негативисты», «пассивные пессимисты», или «лентяи» и «реалисты», распределение нашей выборки по указанным типам личности представлено в табл. 1.

Таблииа 1

Распределение молодых людей, принявших участие в исследовании по типам личности

\begin{tabular}{|l|c|}
\hline \multicolumn{1}{|c|}{ Типы личности } & Количество человек \\
\hline Реалисты & 10 \\
\hline Пассивные оптимисты & 7 \\
\hline Активные пессимисты & 3 \\
\hline Пассивные пессимисты & 19 \\
\hline
\end{tabular}

Очевидно, что большая часть молодых людей из выборки исследования имеют преимущественно отрицательный взгляд на жизнь, они не предпринимают попыток справиться с трудностями при их возникновении, ведут себя осторожно и внимательны к происходящему вокруг. Четверть выборки респондентов имеют выраженный тип личности «реалист», им свойственно преимущественно трезвая оценка ситуации, они способны активно действовать в ситуации, когда понимают, что могут справиться с трудностями. Молодые люди, относящиеся к типу «пассивные оптимисты» (7 чел.), зачастую склонны к позитивной оценке ситуации, им свойственно веселое настроение, но при этом они избегают активных действий, считая, что сложная ситуация разрешится сама собой. У незначительной части респондентов (3 чел.) выявлен тип личности «активный пессимист», для них характерен деструктивный способ преодоления жизненных препятствий из-за их высокой активности и негативного взгляда на жизнь.

Далее нами было проведено сравнение показателей доминирующего психического состояния между группами молодых людей, имеющих разные типы личности. Данное сравнение проведено с целью поиска отличий, связанных с выра- 
женностью оптимизма и активности у респондентов. Результаты статистического анализа представлены в табл. 2.

Таблийа 2

Статистически значимые различия между показателями психического состояния молодых людей в период пандемии и самоизоляции

\begin{tabular}{|l|l|c|c|}
\hline $\begin{array}{c}\text { Параметры психического } \\
\text { состояния }\end{array}$ & \multicolumn{1}{|c|}{ Группы сравнения } & Количество человек & Средний ранг \\
\hline \multirow{4}{*}{ Активация } & Реалисты & 10 & 28,30 \\
\cline { 2 - 4 } & Пассивные оптимисты & 7 & 17,92 \\
\cline { 2 - 4 } & Активные пессимисты & 3 & 28,67 \\
\cline { 2 - 4 } & Пассивные пессимисты & 19 & 13,92 \\
\hline Спокойствие & Реалисты & 10 & 26,20 \\
\cline { 2 - 4 } & Пассивные оптимисты & 7 & 22,92 \\
\cline { 2 - 4 } & Активные пессимисты & 3 & 14,68 \\
\cline { 2 - 4 } & Пассивные пессимисты & 19 & 20,83 \\
\hline
\end{tabular}

Анализируя средние ранги значений, полученных молодыми людьми по представленным параметрам психического состояния, можно сказать, что тем из них, у кого доминируют типы личности «реалист» и «активный пессимист», свойствен более высокий уровень активности в период пандемии и самоизоляции, чем тем, у кого выражены типы «пассивные оптимисты» и «пассивные пессимисты». Они используют активные стратегии для преодоления трудностей, им присуща высокая интенсивность актуализированных мотивов. Полученный результат логичен в плане того, что высокая личностная активность этих молодых людей находит проявление в их доминирующем состоянии. Молодым людям с выраженным реалистичным типом личности также присуще более выраженное спокойствие в период пандемии и самоизоляции (скорее всего пандемия не вызывает у них тревоги, они ощущают контроль над ситуацией и не боятся заболеть).

Таким образом, нами были обнаружены различия в параметрах психического состояния у молодых людей в период пандемии и самоизоляции, обусловленные их личностными особенностями, в частности, выраженной активностью и сбалансированным оптимизмом. Далее мы провели корреляционный анализ с целью оценки взаимосвязи между показателями психического состояния и личностными свойствами молодых людей, принявших участие в исследовании. Отметим, что значимые взаимосвязи обнаружены только между оптимизмом и некоторыми параметрами психического состояния. Связей с активностью респондентов обнаружено не было, полученные данные отражены в табл. 3. 


\section{Выявленные статистически значимые корреляции между параметрами психического состояния молодых людей в период пандемии и самоизоляции и их личностными чертами}

\begin{tabular}{|l|c|}
\hline \multicolumn{1}{|c|}{ Взаимосвязанные параметры } & Показатели тесноты связи \\
\hline Оптимизм $\leftrightarrow$ Спокойствие & $-0,438$ \\
\hline Оптимизм ↔ Психические процессы & $-0,559$ \\
\hline Оптимизм ↔ Переживания & $-0,472$ \\
\hline
\end{tabular}

Обнаруженные отрицательные связи говорят о том, что в исследуемой выборке молодых людей высокий уровень оптимизма обусловлен снижением показателей спокойствия, то есть позитивное отношение к жизни, ожидание положительного исхода событий в условиях неопределенности при пандемии привело к нарастанию беспокойства и тревоги у респондентов. Отрицательная корреляция с показателями психических процессов говорит о том, что оптимизм помогает отстраняться от происходящего, приводит к снижению чувствительности респондентов. В ситуации пандемии и самоизоляции у выраженных оптимистов также была снижена подвижность переживаний. Другими словами, учитывая предыдущие данные, можно сказать, что тревога и беспокойство были довольно устойчивыми их состояниями, несмотря на низкую концентрацию на объективной ситуации.

\section{Выводы и научная новизна.}

Обобщая полученные результаты, можно сделать следующие выводы: большинство молодых людей, принявших участие в исследовании, относятся к типу личности «пассивные пессимисты», то есть характеризуются сниженными показателями оптимизма и активности, что согласуется с научными данными других авторов. Во время стрессовой нагрузки, связанной с пандемией и самоизоляцией, у этих молодых людей отмечались раздражение и нервозность, ощущения возможной угрозы и неблагоприятные предчувствия. Иначе говоря, сниженные показатели оптимизма и активности препятствуют успешной адаптации к стрессовой ситуации и нормализации психического состояния.

Выраженная активность «реалистов» и «активных пессимистов» позволила им выбрать активные стратегии преодоления стресса, они успешно ставят перед собой цели и достигают их, что сопровождается снижением напряжения и сохранением оптимального уровня психического состояния. Сбалансированный оптимизм, свойственный «реалистам», способствовал их спокойствию и ощущению контроля над ситуацией. Однако очень высокие показатели оптимизма, как оказалось, наоборот, связаны с тревогой и беспокойством, что, вероятно, связано с неоправданными положительными ожиданиями в ситуации пандемии и самоизоляции. Таким образом, активность и сбалансированный оптимизм можно 
считать ресурсами нормализации психического состояния у молодых людей в ситуации стресса, связанного с пандемией и самоизоляцией.

Научная новизна исследования заключается в том, что показана связь между оптимизмом и активностью личности и её актуальным состоянием в ситуации стрессовой нагрузки, в то время как автор-разработчик этих понятий Н.Е. Водопьянова выявила их связь лишь с общим благополучием, что расширяет имеющиеся теоретические представления. Продемонстрировано, что оптимизм способствует сохранению спокойствия в стрессовой ситуации, только если находится в пределах нормы, поскольку позволяет реалистично взглянуть на объективные трудности. Полученные данные могут быть использованы при составлении программ профилактики неоптимальных состояний у молодых людей в периоды повышенной стрессовой нагрузки.

1. Алехин А.Н., Дубинина Е.А. Пандемия: клинико-психологический аспект // Артериальная гипертензия. - 2020. - Т. 26, № 3. - С. 312-316.

2. Барсукова Ж. А. Оптимизм и диспозиционная надежда как ресурсы преодоления стрессовых ситуаций в учебной деятельности студентов // Теоретические и практические предпосылки подготовки полилингвальных специалистов в УВО: сборник науч. стат. по материалам VI Международного научно-практического онлайнсеминара (вебинара), Могилев, 03 апреля 2020 г. - Могилев: Могилевский государственный университет имени А.А. Кулешова, 2020. - С. 17-19.

3. Водопьянова Н. Е. Психодиагностика стресса. - Санкт-Петербург: Питер, 2009. $336 \mathrm{c.}$

4. Ильин Е.П. Психофизиология состояний человека. - Санкт-Петербург: Питер: Питер принт, 2015. - 411 с.

5. Левитов Н. Д. Определение психического состояния // Психические состояния: хрестоматия / под ред. Л. В. Куликова. - Санкт-Петербург: Питер, 2010. - С. 4447.

6. Макарова Е. Ю., Цветкова Н. А. Психологические особенности реакций на стресс, обусловленный режимом самоизоляции в период пандемии Covid-19 // E-Scio. 2020. - № 10 (49). - С. 145-157.

7. Прохоров А. О., Юсупов М. Г. Рефлексивный слой познавательных состояний // Экспериментальная психология. - 2017. - Т. 10, №2 - С. 91-103.

8. Hall R.C., Chapman M. J. The 1995 Kikwit Ebola outbreak: lessons hospitals and physicians can apply to future viral epidemics // Gen Hosp Psychiatry. - 2008. - Vol. 30, № 5. - P. 446-452.

9. Xiang Y-T., Yang Y., Li W. Timely mental health care for the 2019 novel coronavirus outbreak is urgently needed // Lancet Psychiatry. - 2020. - Vol. 7, № 3. - P. 228-229.

10. Zhang J., Lu H., Zeng H. The differential psychological distress of populations affected by the COVID-19 pandemic // Brain Behav Immun. - 2020. - № 87. - P. 49-50.

\section{References}

1. Alekhin A. N., Dubinina E. A. Pandemiya: kliniko-psihologicheskij aspekt // Arterial'naya gipertenziya. - 2020. - T. 26, № 3. - S. 312-316.

2. Barsukova Zh. A. Optimizm i dispozicionnaya nadezhda kak resursy preodoleniya stressovyh situacij v uchebnoj deyatel'nosti studentov // Teoreticheskie i prakticheskie predposylki podgotovki polilingval'nyh specialistov v UVO: sbornik nauch. stat. po mate- 
rialam VI Mezhdunarodnogo nauchno-prakticheskogo onlajn-seminara (vebinara), Mogilev, 03 aprelya 2020 g. - Mogilev: Mogilevskij gosudarstvennyj universitet imeni A. A. Kuleshova, 2020. - S. 17-19.

3. Vodop'yanova N.E. Psihodiagnostika stressa. - Sankt-Peterburg: Piter, 2009. - 336 s.

4. Il'in E. P. Psihofiziologiya sostoyanij cheloveka. - Sankt-Peterburg: Piter: Piter print, 2015. $-411 \mathrm{~s}$.

5. Levitov N. D. Opredelenie psihicheskogo sostoyaniya // Psihicheskie sostoyaniya: hrestomatiya / pod red. L. V. Kulikova. - Sankt-Peterburg: Piter, 2010. - S. 44-47.

6. Makarova E. Yu., Cvetkova N. A. Psihologicheskie osobennosti reakcij na stress, obuslovlennyj rezhimom samoizolyacii v period pandemii Sovid-19 // E-Scio. - 2020. № 10 (49). - S. 145-157.

7. Prohorov A.O., Yusupov M.G. Refleksivnyj sloj poznavatel'nyh sostoyanij // Eksperimental'naya psihologiya. - 2017. - T. 10, №2 - S. 91-103.

() И.И. Черемискина, 2021

Для цитирования: Черемискина И. И. Оптимизм и активность как ресурсы нормализации психического состояния у молодых людей в период пандемии и самоизоляции // Территория новых возможностей. Вестник Владивостокского государственного университета экономики и сервиса. - 2021. - Т. 13, № 3. - С. 197-206.

For citation: Cheremiskina I. I. Optimism and activism as resources for normalizing mental health in young people during pandemic and self-isolation, The Territory of New Opportunities. The Herald of Vladivostok State University of Economics and Service, 2021, Vol. 13, № 3, pp. 197-206.

DOI https://doi.org/10.24866/VVSU/2073-3984/2021-3/197-206

Дата поступления: 17.08.2021. 